\title{
Mössbauer Spectrometry in FeMoCuB-Type Nanocrystalline Alloys
}

\author{
M. Miglierini \\ Department of Nuclear Physics and Technology \\ Slovak University of Technology \\ Ilkovičova 3, 81219 Bratislava, Slovakia
}

\begin{abstract}
The applicability of the Mössbauer spectrometry to the study of $\mathrm{Fe}_{91-x} \mathrm{Mo}_{8} \mathrm{Cu}_{1} \mathrm{~B}_{x}(x=12,15,17)$ nanocrystalline alloys prepared by controlled annealing of ribbon-shaped amorphous precursors is demonstrated. Differences between both surfaces of the ribbons are pointed out to be due to preparation conditions. Conclusions from the Mössbauer spectrometry are supported by diffraction of synchrotron radiation, X-ray diffraction, and atomic field microscopy investigations.
\end{abstract}

PACS numbers: 75.50.Tt, 61.46.+w, 61.66.-f, 76.80.+y

\section{Introduction}

The Mössbauer spectrometry provides a unique possibility for simultaneous investigation of structural arrangement and magnetic states of the resonant atoms via their hyperfine interactions [1]. They sensitively reflect changes in the chemical and/or topological short-range atomic order. This is especially suited for the study of nanocrystalline alloys featuring crystalline and amorphous phases. The former is characterised by a crystalline lattice with accurately determined atomic positions whereas the latter lacks any structural periodicity.

\section{Experimental details}

Amorphous precursors of the $\mathrm{Fe}_{91-x} \mathrm{Mo}_{8} \mathrm{Cu}_{1} \mathrm{~B}_{x}(x=12,15,17)$ alloy were prepared by the method of planar flow casting at the Institute of Physics, SAS, in Bratislava. The resulting ribbons (10 mm wide, $20-25 \mu \mathrm{m}$ thick) were annealed at temperatures from 330 up to $650^{\circ} \mathrm{C}$ for one hour under high vacuum conditions to obtain samples with different contents of crystalline phases.

The Mössbauer effect measurements were performed with a ${ }^{57} \mathrm{Co} / \mathrm{Rh}$ source in transmission geometry (TMS) and using the detection of conversion electrons 
(CEMS). A conventional constant acceleration spectrometer was calibrated by $\alpha$-Fe foil at $300 \mathrm{~K}$. All spectra were evaluated using the Confit software [2].

X-ray diffraction (XRD) was performed with $\mathrm{Cu} K_{\alpha}$ radiation. Diffraction of synchrotron radiation $(0.178 \mathrm{~nm})$ was accomplished at BESSY Berlin. Topographic images were acquired by the atom field microscopy (AFM) Explorer microscope in a non-contact mode with tip radius of less than $10 \mathrm{~nm}$.

\section{Results and discussion}

Figure 1 illustrates TMS of selected samples in the as-quenched state and after annealing at the indicated temperatures. The effect of composition is readily observed by noticeable changes in the spectral shapes. They vary from pure (though broadened) paramagnetic doublet for $x=12$ (Fig. 1a) to magnetically broadened patterns which imply weak ( $x=15$ in Fig. 1b) and more pronounced $(x=17$ in Fig. 1c) contribution of magnetic hyperfine interactions due to increasing boron concentration. Consequently, the Curie temperature is also increased [3].

(a)
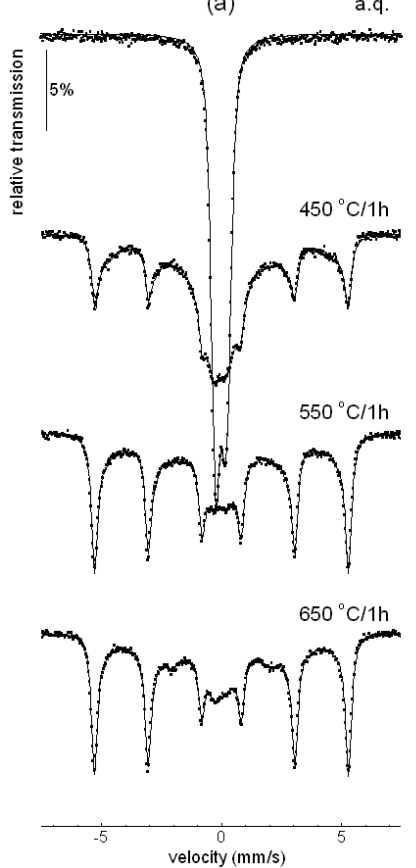

(b)
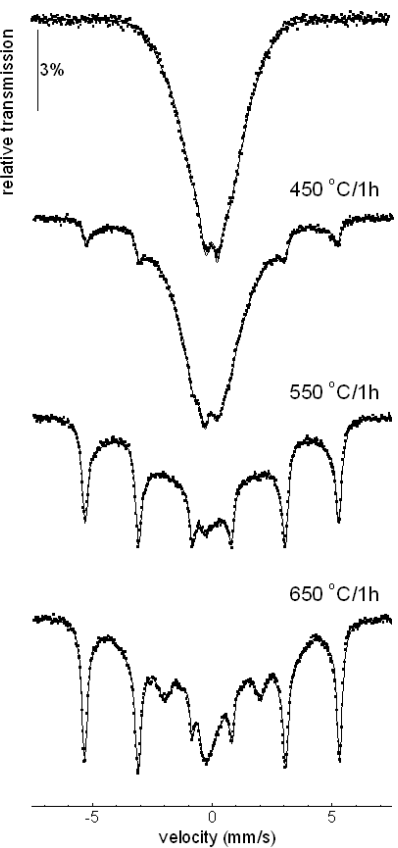

(c)
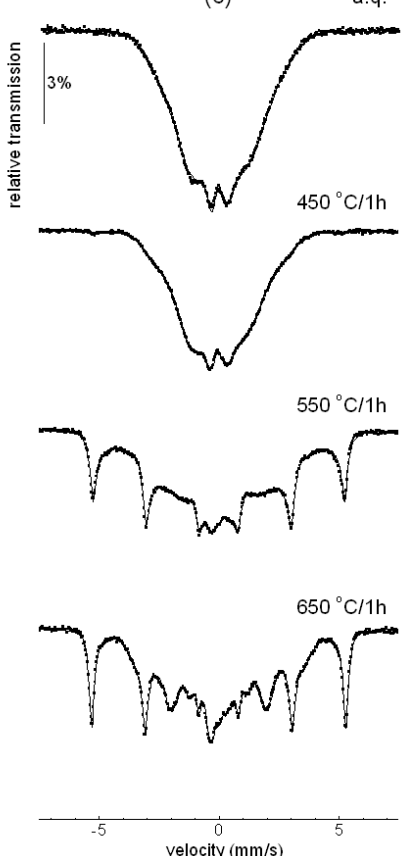

Fig. 1. TMS of $\mathrm{Fe}_{91-x} \mathrm{Mo}_{8} \mathrm{Cu}_{1} \mathrm{~B}_{x}$ alloy annealed at the indicated temperatures (a.q. — as-quenched state) for $x=12$ (a), 15 (b), and 17 (c).

After annealing, sharp spectral lines appear that indicate a presence of crystalline phases. In the first stage of crystallization, they correspond to bcc-Fe phase 


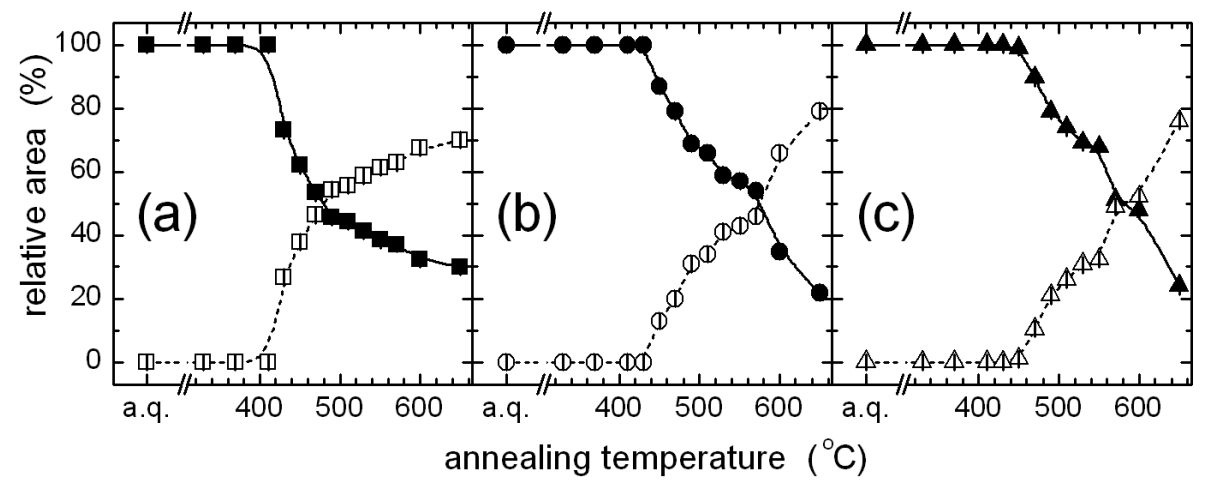

Fig. 2. Relative areas of amorphous (solid symbols) and crystalline (open symbols) contributions to the TMS of $\mathrm{Fe}_{91-x} \mathrm{Mo}_{8} \mathrm{Cu}_{1} \mathrm{~B}_{x}$ alloy plotted against temperature of annealing (a.q. - as-quenched state) for $x=12$ (a), 15 (b), and 17 (c).

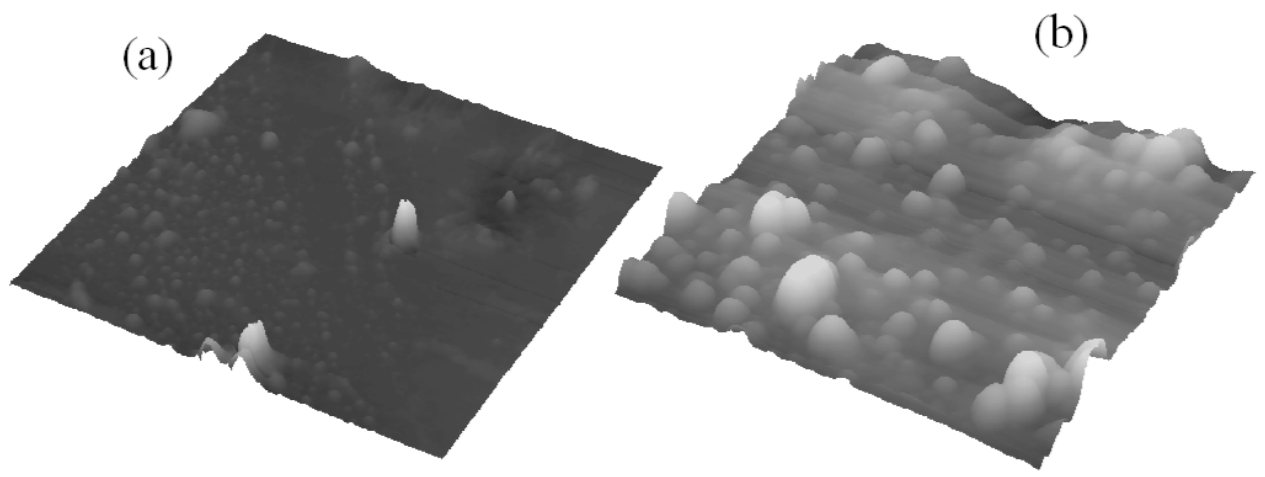

Fig. 3. AFM images of the air (a) and wheel (b) side of $\mathrm{Fe}_{79} \mathrm{Mo}_{8} \mathrm{Cu}_{1} \mathrm{~B}_{12}$ ribbon.

with minute inclusions of Mo [4]. Again, depending on the composition of the master alloy, the crystallization starts at different temperatures of annealing. While in $x=12$ the presence of bcc-Fe(Mo) is well developed already after annealing at $450^{\circ} \mathrm{C}, x=15$ shows less contents of crystallites, and for $x=17$ the crystallization just starts. Quantification of the relative fractions of crystalline and amorphous regions in the investigated alloys is seen in Fig. 2.

On the other hand, presence of other crystalline phases like $\mathrm{Mo}_{2} \mathrm{FeB}_{2}$ and $\mathrm{Fe}_{3} \mathrm{~B}[4]$ is revealed at higher temperatures of annealing. Similarly, composition dependent onset of the second crystallization stage is documented by appearance of additional Mössbauer lines in Fig. 1.

We have scanned both surfaces of the $\mathrm{Fe}_{79} \mathrm{Mo}_{8} \mathrm{Cu}_{1} \mathrm{~B}_{12}$ as-cast ribbon by AFM. The images in Fig. 3 show traces of crystallites on the air side and quite high number of crystalline agglomerates on the wheel side. 

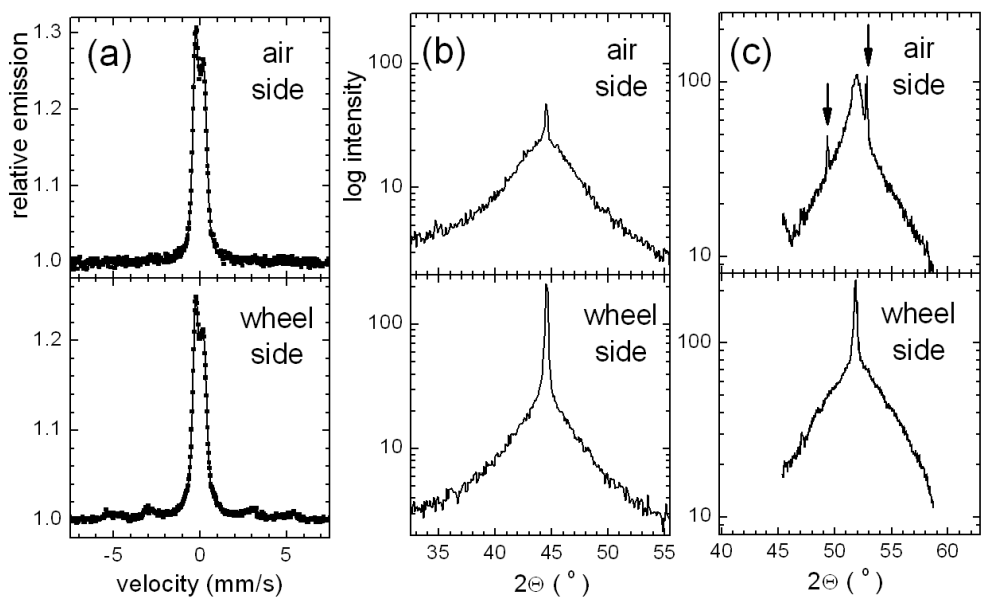

Fig. 4. CEMS (a), XRD (b), and diffraction of synchrotron radiation (c) of $\mathrm{Fe}_{79} \mathrm{Mo}_{8} \mathrm{Cu}_{1} \mathrm{~B}_{12}$ alloy from both sides of the ribbon-shaped sample. Arrows in (c) indicate reflections of the $\mathrm{Mo}_{2} \mathrm{FeB}_{2}$ crystalline phase.

As demonstrated by CEMS in Fig. 4a, a presence of quenched-in crystallites was confirmed on the wheel side of the ribbon whereas the air side was found to be amorphous in the frame of experimental restrictions of this technique. Inhomogeneity of crystallization process induced by rapid quenching is shown to be responsible for enhanced crystallization at the surface [5]. Inspection of both surfaces by XRD and by diffraction of synchrotron radiation (the results presented in Fig. 4b and c, respectively) unveiled along with bcc-Fe(Mo) tiny crystals $(<2 \mathrm{~nm})$ also traces of $\mathrm{Mo}_{2} \mathrm{FeB}_{2}$ phase on the air side of the ribbon only. Conventional XRD as well as CEMS were not able to detect this crystalline phase mainly due to extremely small size of the crystals and also due to their small volume fraction. In this respect, the limitations of the Mössbauer spectrometry must be considered.

\section{Acknowledgments}

Supported by VEGA 1/4011/07, APVT-52-008404, and MSM6198959218.

\section{References}

[1] M. Miglierini, M. Seberíni, I. Tóth, R. Gröne, K. Vitázek, J.-M. Grenèche, B. Idzikowski, Scr. Mater. 44, 1353 (2001).

[2] T. Žak, Y. Jirásková, Surf. Interf. Anal. 38, 710 (2006).

[3] E. Illeková, D. Janičkovič, M. Miglierini, I. Škorvánek, P. Švec, J. Magn. Magn. Mater. 304, e636 (2006).

[4] M. Pavúk, M. Miglierini, M. Vůjtek, M. Mashlan, R. Zbořil, Y. Jirásková, J. Phys., Condens. Matter. 19, 216219 (2007).

[5] I. Bibicu, J.S. Garitaonandia, F. Plazaola, E. Apiñaniz, J. Non-Cryst. Solids 287, 277 (2001). 